\title{
Hydrogen Peroxide Formation and Stoichiometry of Hydroxylation Reactions Catalyzed by Highly Purified Liver Microsomal Cytochrome $P-450^{1}$
}

\author{
GERALD D. NORDBLOM AND MINOR J. COON \\ Department of Biological Chemistry, Medical School, The University of Michigan, Ann Arbor, \\ Michigan 48109
}

Received July 23, 1976

\begin{abstract}
The stoichiometry of hydroxylation reactions catalyzed by cytochrome $P-450$ was studied in a reconstituted enzyme system containing the highly purified cytochrome from phenobarbital-induced rabbit liver microsomes. Hydrogen peroxide was shown to be formed in the reconstituted system in the presence of NADPH and oxygen; the amount of peroxide produced varied with the substrated added. NADPH oxidation, oxygen consumption, and total product formation (sum of hydroxylated compound and hydrogen peroxide) were shown to be equimolar when cyclohexane, benzphetamine, or dimethylaniline served as the substrate. The stoichiometry observed represents the sum of two activities associated with cytochrome $P-450$. These are (1) hydroxylase activity: $\mathrm{NADPH}+\mathrm{H}^{+}+\mathrm{O}_{2}+\mathrm{RH} \rightarrow \mathrm{NADP}^{+}+\mathrm{H}_{2} \mathrm{O}+\mathrm{ROH}$; and (2) oxidase activity: $\mathrm{NADPH}+$ $\mathrm{H}^{+}+\mathrm{O}_{2} \rightarrow \mathrm{NADP}^{+}+\mathrm{H}_{2} \mathrm{O}_{2}$. Benzylamphetamine (desmethylbenzphetamine) acts as a pseudosubstrate in that it stimulates peroxide formation to the same extent as the parent compound (benzphetamine), but does not undergo hydroxylation. Accordingly, when benzylamphetamine alone is added in control experiments to correct for the NADPH and $\mathrm{O}_{2}$ consumption not associated with benzphetamine hydroxylation, the expected 1:1:1 stoichiometry for NADPH oxidation, $\mathrm{O}_{2}$ consumption, and formaldehyde formation in the hydroxylation reaction is observed.
\end{abstract}

Cytochrome $P-450$, the terminal oxidase of the liver microsomal mixed-function oxidase system, catalyzes the NADPH-dependent hydroxylation of a wide variety of drugs, steroids, fatty acids, and alkanes. According to the general equation for a mixed-function oxidation reaction (2), the stoichiometry of NADPH oxidation, oxygen consumption, and product formation is 1:1:1. Experimental values obtained with liver microsomal suspensions have varied with the conditions employed, and various procedures have been used to correct for the endogenous rates of NADPH and oxy. gen utilization (3-8). In our earlier investigation of the stoichiometry of drug demethylation using resolved and partially

\footnotetext{
${ }^{1}$ This research was supported by Grant BMS7101195 from the National Science Foundation and Grant AM-10339 from the United States Public Health Service. A preliminary report of part of this investigation has been presented (1).
}

purified enzyme fractions, the addition of catalase reduced the oxygen uptake to the expected value (9).

In the present paper, the stoichiometry of the hydroxylation of several substrates was studied with a reconstituted system containing highly purified $P-450_{\mathrm{LM}}{ }^{2}$ and NADPH-cytochrome $P-450$ reductase. Hydrogen peroxide was shown to be produced in varying amounts depending upon the substrate present. The expected stoichiometry was obtained for NADPH and oxygen utilization and for product formation, with several substrates, provided that hydrogen peroxide formation was also taken into account. The NADPH-dependent production of hydrogen peroxide by liver microsomes was first reported by Gillette et al. (10) and

${ }^{2}$ Abbreviations used: $P-450_{\mathrm{LM}}$, liver microsomal cytochrome $P-450 ; P-450_{\mathrm{LM} 2}$, phenobarbital-inducible form of $P-450_{1 M}$; dilauroyl-GPC, dilauroylglyceryl-3phosphorylcholine; DEAE, diethylaminoethyl. 
has also been described by others in more recent studies (11-14).

\section{EXPERIMENTAL PROCEDURES}

$P-450_{\mathrm{LM}}$ was isolated from liver microsomes of phenobarbital-induced rabbits as described previously $(15,16)$. The procedure involves fractionation of cholate-solubilized microsomes with polyethylene glycol, followed by DEAE-cellulose and hydroxylapatite column chromatography. The final preparation, which is electrophoretically homogeneous, contains the form of $P-450_{\mathrm{LM}}$ induced by phenobarbital. This form has been designated by its relative electrophoretic mobility as $P-450_{\mathrm{LM} 2}$ (17). The preparations used in the present study had the following specific content, given as nanomoles per milligram of protein: microsomes, 3.4; fraction precipitated by polyethylene glycol, 6.0; DEAE-cellulose column eluate, 8.6; and hydroxylapatite column eluate, 16.9. In all cases, except with microsomes, the enzyme system was reconstituted with rabbit liver microsomal NADPH-cytochrome $P-450$ reductase (specific activity, $19.2 \mu \mathrm{mol}$ of cytochrome $c$ reduced/ $\mathrm{min} / \mathrm{mg}$ of protein at $30^{\circ} \mathrm{C}$ ) purified by a modification of methods described eariler $(16,18)$ and dilauroylGPC.

$d$-Benzphetamine and $d$-benzylamphetamine (desmethylbenzphetamine) were generously provided by Dr. P. W. McConnell of the Upjohn Company and $d-\left[N\right.$-methyl- $\left.{ }^{14} \mathrm{C}\right]$ benzphetamine was provided by Dr. A. Y. H. Lu, Hoffmann-La Roche, Inc.; $\left[\mathrm{U}-{ }^{14} \mathrm{C}\right]$ cyclohexane was obtained from Amersham/ Searle, dilauroyl-GPC was from Serdary Research Laboratories, London, Ontario, and bovine liver catalase (twice recrystallized) and NADPH were from Sigma. $N, N$-Dimethylaniline was purchased from Aldrich and redistilled, while cyclohexane from Eastman Chemical (Spectro ACS grade) was used without further purification.

Assay of components in hydroxylation reactions. Rates of NADPH oxidation and product formation were determined at $30^{\circ} \mathrm{C}$ in $1.0-\mathrm{ml}$ reaction mixtures containing $P-450_{\mathrm{LM}}(0.1 \mu \mathrm{M})$, NADPH-cytochrome $P-450$ reductase preparation ( $36 \mu \mathrm{g}$ of protein $/ \mathrm{ml}$ ), dilauroyl-GPC $(30 \mu \mathrm{g} / \mathrm{ml}), 0.1 \mathrm{M}$ potassium phosphate buffer, pH 7.4, substrate (10 mM cyclohexane or $N, N$-dimethylanilinc, added in $0.01 \mathrm{ml}$ of methanol, or $1.0 \mathrm{~mm}$ benzphetamine), and $0.1 \mathrm{~mm}$ NADPH. In some experiments, benzylamphetamine was added at a final $1.0 \mathrm{~mm}$ concentration in place of the usual substrates. In all such assays $P-450_{\mathrm{LM}}$ was the rate-limiting component, and the molar ratio of reductase to $P-450_{\mathrm{LM}}$ was about 5:1. In microsomes, in contrast, $P-450_{\mathrm{LM}}$ is in excess. The order of addition and other conditions were described earlier (16). Oxyyen consumption was measured under the same conditions, but in a $3-\mathrm{ml}$ reaction mixture, with a Clark-type electrode used in conjunction with a Heath EU-20B recorder. NADPH was the last addition, and its consumption was measured at $340 \mathrm{~nm}$ with a spectrophotometer equipped with a multiple sample absorbance recorder. Formaldehyde formation from $N, N$-dimethylaniline was measured by the method of Nash (19) as modified by Cochin and Axelrod (20). The $N$-demethylation of radioactive benzphetamine $\left(1.2 \times 10^{5} \mathrm{cpm} / \mu \mathrm{mol}\right)$ was determined by the method of Poland and Nebert (21) and the hydroxylation of radioactive cyclohexane $(1.8 \times$ $10^{5} \mathrm{cpm} / \mu \mathrm{mol}$ ) was determined by isolation of the resulting cyclohexanol according to the chromatographic procedure of Gholson et al. (22). Hydrogen peroxide production was measured by the change in rate of oxygen consumption upon the addition of 3 $\mu \mathrm{g}$ (108 units) of catalase to the reaction mixture. Catalase had no effect on the rates of NADPH oxidation or of product formation from the added substrates. For comparison, rates of peroxide formation were also determined in the same experiments by the ferrithiocyanate method described by Thurman et al. (11), and the values obtained by the two methods were found to be in excellent agreement.

\section{RESULTS}

Stoichiometry of substrate hydroxylation. As shown in Table I, highly purified

TABLE I

Stoichiometry of Cytochrome P-450-Catalyzed Reactions in Reconstituted System ${ }^{\prime}$

\begin{tabular}{|c|c|c|c|c|c|}
\hline \multirow[t]{2}{*}{ Substrate } & \multicolumn{4}{|c|}{$\begin{array}{l}\text { Change in components }(\mathrm{nmol} / \mathrm{min} / \mathrm{nmol} \text { of } P \text { - } \\
\left.450_{\mathrm{LM}}\right)\end{array}$} & \multirow[t]{2}{*}{$\begin{array}{l}\text { NADPH } / \mathrm{O}_{2} / \text { prod- } \\
\text { uct }+\mathrm{H}_{2} \mathrm{O}_{2}\end{array}$} \\
\hline & -NADPH & $-\mathrm{O}_{2}$ & Product $^{b}$ & $\mathrm{H}_{2} \mathrm{O}_{2}$ & \\
\hline Benzphetamine & 77 & 75 & 33 & 42 & $1.0 / 1.0 / 1.0$ \\
\hline Cyclohexane & 66 & 62 & 50 & 17 & $1.0 / 0.9 / 1.0$ \\
\hline$N, N$-Dimethylaniline & 53 & 56 & 30 & 25 & $1.0 / 1.1 / 1.0$ \\
\hline None & 21 & 22 & - & 21 & $1.0 / 1.0 / 1.0$ \\
\hline
\end{tabular}

"In this and subsequent tables, the data presented are average values of three experiments. The $P-450_{\mathrm{LM} 2}$ had a specific content of $16.9 \mathrm{nmol} / \mathrm{mg}$ of protein, and the $P-450_{\mathrm{LM}_{2}}$ :reductase molar ratio was 1:5.

"Formaldehyde was measured as the product of benzphetamine and dimethylaniline hydroxylation, and. cyclohexanol was measured as the product formed from cyclohexane. 
$P-450$ M catalyzes the formation of $\mathrm{H}_{2} \mathrm{O}_{2}$ from NADPH and oxygen in the reconstituted enzyme system in either the presence or the absence of substrate. Peroxide formation was much greater with benzphetamine than with the other substrates tested. Therefore, the oxygen and NADPH consumed in peroxide formation must be taken into account in studying the stoichiometry of each $P-450_{\mathrm{LM}}$-mediated hydroxylation reaction. The results presented show that, when this is done, NADPH oxidation, oxygen consumption, and total product formation are equimolar. Control experiments established that the NADPH oxidase activity observed in the absence of substrate is due almost entirely to the cytochrome $P-450$, rather than the reductase. In other experiments with the reconstituted system, cyclohexanol was shown by gas-liquid chromatography to be the only product formed from cyclohexane, and benzylamphetamine and $N$-methylaniline were shown to be the only products (other than formaldehyde) formed from benzphetamine and dimethylaniline, respectively.

Effect of $P-450_{L M}$ purification on relative amounts of product and hydrogen peroxide formed. Because of the relatively large amount of peroxide formed, particularly during the hydroxylation of benzphetamine (see Table I), the possibility was considered that the cytochrome becomes more readily autoxidizable, and therefore produces more hydrogen peroxide, upon solubilization from microsomes and purification. The data in Table II compare the changes in reaction components during benzphetamine demethylation in microsomes at two intermediate stages in the purification of $P-450_{\mathrm{LM}}$ and with a homogeneous preparation of the cytochrome. The low efficiency of benzphetamine hydroxylation relative to NADPH oxidation is seen to be due to the effect of this particular substrate and not to changes occurring in the enzyme during solubilization from the membrane and subsequent purification. The increased turnover number (moles of benzphetamine demethylated per minute per mole of $P-450_{\mathrm{LM} 2}$ ) during purification is undoubtedly due to removal of other forms of $P-450_{\mathrm{LM}}$ known to have less activity toward this substrate (17).

Effect of benzphetamine and benzylamphetamine on hydrogen peroxide formation. Results already presented (Table I) indicate that the amount of hydrogen peroxide formed varies with the substrate present. Rates of hydrogen peroxide formation in the presence of dimethylaniline and cyclohexane were similar to those observed in the absence of substrate; in contrast, benzphetamine caused a twofold stimulation of peroxide formation. The data in Table III show that the product of benzphetamine demethylation, benzylamphetamine, has a similar effect to that of the parent compound. Benzylamphetamine acts as a pseudosubstrate in that it does not undergo hydroxylation by $P$ $450_{\mathrm{LM} 2}$ (as shown by gas-liquid chromatography in this laboratory), but stimulates electron transfer to yield hydrogen peroxide to the same extent as that seen with benzphetamine. It should be noted that, with the desmethyl compound present, hydrogen peroxide formation, NADPH oxidation, and $\mathrm{O}_{2}$ consumption are equimolar. Accordingly, benzylamphetamine may be added in control experiments (in

TABLE II

Stoichiometry of Benzphetamine Hydroxylation by $P-450_{\mathrm{Lm}}$ at Various Stages of Purification

\begin{tabular}{|c|c|c|c|c|c|}
\hline \multirow[t]{2}{*}{ Preparation } & \multicolumn{4}{|c|}{$\begin{array}{l}\text { Change in components }(\mathrm{nmol} / \mathrm{min} / \mathrm{nmol} \text { of } P \text { - } \\
\left.\qquad 450_{\mathrm{LM}}\right)\end{array}$} & \multirow[t]{2}{*}{$\begin{array}{l}\text { Efficiency } \\
(\%)\end{array}$} \\
\hline & -NADPH & $-\mathrm{O}_{2}$ & $\mathrm{CH}_{2} \mathrm{O}$ & $\mathrm{H}_{2} \mathrm{O}_{2}$ & \\
\hline Microsomes & 9 & 10 & 4 & 6 & 44 \\
\hline Polyethylene glycol fraction & 34 & 35 & 11 & 16 & 44 \\
\hline DEAE-cellulose column eluate & 67 & 64 & 31 & 33 & 47 \\
\hline Hydroxylapatite column eluate & 77 & 75 & 33 & 42 & 43 \\
\hline
\end{tabular}

${ }^{a}$ Efficiency is expressed as the amount of substrate hydroxylated (determined by formaldehyde formation) relative to NADPH oxidized. 
TABLE III

Stoichiometry with Benzphetamine or Benzylamphetamine Present"

\begin{tabular}{|c|c|c|c|c|c|c|}
\hline \multirow[t]{2}{*}{ Expt } & \multirow[t]{2}{*}{ Compound added } & \multicolumn{4}{|c|}{$\begin{array}{l}\text { Change in components }(\mathrm{nmol} / \mathrm{min} / \mathrm{nmol} \text { of } P \text { - } \\
\left.450_{\mathrm{LM}}\right)\end{array}$} & \multirow{2}{*}{$\begin{array}{l}\text { Total prod- } \\
\text { uct }\left(\mathrm{CH}_{2} \mathrm{O}\right. \\
\left.\quad+\mathrm{H}_{2} \mathrm{O}_{2}\right)\end{array}$} \\
\hline & & -NADPH & $-\mathrm{O}_{2}$ & $\mathrm{CH}_{2} \mathrm{O}$ & $\mathrm{H}_{2} \mathrm{O}_{2}$ & \\
\hline A & Benzphetamine & $\begin{array}{c}77 \\
(1.0)\end{array}$ & $\begin{array}{c}75 \\
(1.0)\end{array}$ & $\begin{array}{c}33 \\
(0.4)\end{array}$ & $\begin{array}{c}42 \\
(0.6)\end{array}$ & $\begin{array}{c}75 \\
(1.0)\end{array}$ \\
\hline B & $\begin{array}{l}\text { Benzylampheta- } \\
\text { mine }\end{array}$ & $\begin{array}{c}45 \\
(1.0)\end{array}$ & $\begin{array}{c}44 \\
(1.0)\end{array}$ & - & $\begin{array}{c}42 \\
(0.9)\end{array}$ & - \\
\hline A minus $B$ & & $\begin{array}{c}32 \\
(1.0)\end{array}$ & $\begin{array}{c}31 \\
(1.0)\end{array}$ & $\begin{array}{c}33 \\
(1.0)\end{array}$ & - & - \\
\hline
\end{tabular}

" Rates relative to that of NADPH oxidation are given in parentheses. The $P-450_{\mathrm{LM} 2}$ had a specific content of $16.9 \mathrm{nmol} / \mathrm{mg}$ of protein, and the cytochrome:reductase molar ratio was $1: 5$.

the absence of benzphetamine) to correct for the NADPH and $\mathrm{O}_{2}$ consumption not associated with benzphetamine hydroxylation, and the expected 1:1:1 stoichiometry of the hydroxylation reaction is then obtained, as shown in Table III.

\section{DISCUSSION}

The results presented show that two reactions, each involving a two-electron transfer to molecular oxygen, contribute to the stoichiometry observed with purified $P-450_{\mathrm{LM}}$ in the reconstituted system: hydroxylase activity, where $\mathrm{RH}$ represents substrate,

$$
\begin{aligned}
\mathrm{NADPH} & +\mathrm{H}^{+}+\mathrm{O}_{2}+\mathrm{RH} \\
& \rightarrow \mathrm{NADP}^{+}+\mathrm{H}_{2} \mathrm{O}+\mathrm{ROH} ;
\end{aligned}
$$

NADPH oxidase activity,

$$
\begin{aligned}
\mathrm{NADPH}+\mathrm{H}^{+}+ & \mathrm{O}_{2} \\
& \rightarrow \mathrm{NADP}^{+}+\mathrm{H}_{2} \mathrm{O}_{2} .
\end{aligned}
$$

The latter reaction is apparently due to the autoxidation of the reduced cytochrome in the presence of oxygen. The finding that hydrogen peroxide is produced by the purified cytochrome is particularly interesting, in view of the fact that such enzyme preparations are known to utilize peroxide for the hydroxylation of a variety of substrates in the absence of NADPH and molecular oxygen $(23,24)$. It is possible, therefore, that Reaction [2] may contribute to the overall hydroxylation capability of this enzyme system. In an earlier study (9) carried out under somewhat different conditions with a partially purified $P$ $450_{\mathrm{LM}}$ preparation, added catalase ap- peared to decrease the oxygen uptake during benzphetamine demethylation to a value corresponding to the amount of NADPH oxidized and formaldehyde formed. The significance of that earlier finding is questionable, since the present results with a system containing highly purified $P-450_{\mathrm{LM}}$ and reductase establish that added catalase has the expected effect of generating $0.5 \mathrm{~mol}$ of oxygen per mole of hydrogen peroxide present.

Our results indicate that the nature of the substrate alters the efficiency of the enzyme, i.e., the relative contributions of hydroxylase and oxidase activities in the overall consumption of NADPH and oxygen. Hydroxylase activity exceeds oxidase activity when cyclohexane or dimethylaniline is present, whereas the reverse is true with benzphetamine. Since benzylamphetamine acts as a pseudosubstrate with an effect like that of benzphetamine, it appears that certain structural features of the substrate help determine the fate of the oxygen molecule undergoing reduction in this enzyme system. Thus, the substrate alters the relative extent of oxygen reduction to hydrogen peroxide, as compared to oxygen reduction to water accompanied by substrate hydroxylation. These two processes may involve a common species of activated oxygen, as proposed in a previous mechanistic study (23). Staudt et al. (8) found that perfluoro- $n$-hexane acts as an uncoupler when added to rabbit liver microsomal suspensions; no product was formed, and $2 \mathrm{~mol}$ of NADPH were oxidized per mole of oxygen. Their findings suggest that the oxygen was reduced to 
water, which would be expected since microsomes generally contain adsorbed catalase. Their work agrees well with our own when catalase is added to our reaction mixtures.

\section{ACKNOWLEDGMENTS}

We are grateful to Barbara M. Michniewicz for skillful assistance in the research.

\section{REFERENCES}

1. Nordblom, G. D., and Coon, M. J. (1976) Fed. Proc. 35, 81.

2. Mason, H. S. (1957) Science 125, 1185-1188.

3. ORRenius, S. (1965) J. Cell Biol. 26, 713-723.

4. Estabrook, R. W., and Cohen, B. (1969) in Microsomes and Drug Oxidations (Gillette, J. R., Conney, A. H., Cosmides, G. J., Estabrook, R. W., Fouts, J. R., and Mannering, G. J., eds.), pp. 95-109, Academic Press, New York.

5. Stripp, B., Zampaglione, N., Hamrick, M., and Gillette, J. R. (1972) Mol. Pharmacol. 8 , 189-196.

6. Sasame, H. A., Mitchell, J. R., Thorgeirsson, S., ANd Gillette, J. R. (1973) Drug Metab. Disp. 1, 150-155.

7. Shozmaker, D. D., and Hamrick, M. E. (1974) Biochem. Pharmacol. 23, 2325-2327.

8. Staudt, H., Lichtenberger, F., and Ullrich, V. (1974) Eur. J. Biochem. 46, 99-106.

9. Lu, A. Y. H., Strobel, H. W., ANd Coon, M. J. (1970) Mol. Pharmacol. 6, 213-220.
10. Gillette, J. R., Brodie, B. B., and LaDu, B. N. (1957) J. Pharmacol. Exp. Ther. 119, 532-540.

11. Thurman, R. G., Ley, H. G., and Scholz, R. (1972) Eur. J. Biochem. 25, 420-430.

12. Boveris, A., Oshino, N., ANd Chance, B. (1972) Biochem. J. 128, 617-630.

13. Hildebrandt, A. G., Speck, M., And Roots, I. (1973) Biochem. Biophys. Res. Commun. 54, 968-975.

14. Hildebrandt, A. G., ANd Roots, I. (1975) Arch. Biochem. Biophys. 171, 385-392.

15. van der Hoeven, T. A., Haugen, D. A., ANd Coon, M. J. (1974) Biochem. Biophys. Res. Commun. 60, 569-575.

16. van DER Hoeven, T. A., ANd CoON, M. J. (1974) J. Biol. Chem. 249, 6302-6310.

17. Haugen, D. A., van der Hoeven, T. A., and Coon, M. J. (1975) J. Biol. Chem. 250, 35673570.

18. Vermiliun, J. L., anj Coon, M. J. (1974) Biochem. Biophys. Res. Commun. 60, 1315-1322.

19. NASH, T. (1953) Biochem. J. 55, 416-421.

20. CoChin, J., ANd AXelrod, J. (1959) J. Pharmacol. Exp. Ther. 125, 105-110.

21. Poland; A. P., and Nebert, D. W. (1973) $J$. Pharmacol. Exp. Ther. 184, 269-277.

22. Gholson, R. K., Baptist, J. N., and Coon, M. J. (1963) Biochemistry 2, 1155-1159.

23. Nordblom, G. D., White, R. E., and Coon, M. J. (1976) Arch. Biochem. Biophys. 175, 524533.

24. Hrycay, E. G., Gustafsson, J., IngelmanSundberg, M., ANd Ernster, I (1975) Biochem. Biophys. Res. Commun. 66, 209-216. 